\title{
Welding Cylinder Head: The Effect of Filler Variations and Post Weld Heat Treatment (PWHT) on Microstructure and Mechanical Properties on TIG Welded Cast Iron FC 250
}

\author{
Wikan Jatimurti ${ }^{1, *}$, Mas Irfan P. Hidayat ${ }^{1}$, Rochman Rochiem $^{1}$ and Meilati Pasca Muna ${ }^{1}$ \\ ${ }^{1}$ Materials and Metallurgical Engineering, Faculty of Industrial Technology, Institut Teknologi Sepuluh Nopember (ITS), Surabaya \\ 60111, Indonesia
}

\begin{abstract}
Cylinder head made from grey cast iron, is one of critical engine part which work on high temperature and pressure. The condition which occurs continuously during engine operation causes wear which identified as a fretting failure. Therefore repairing process is needed by using Tungsten Inert Gas (TIG) welding. By considering the working condition and the materials, welding parameters are used 140A current, $100 \%$ Argon, DCEP and preheat at $250^{\circ} \mathrm{C}$. The welding process is done on specimen sample of cylinder head which fretting failure by using Ni-CI, NiFe, NiFe-1 dan 308L filler variation for each specimen and done by PWHT at temperature $650^{\circ} \mathrm{C}$ which holding time 90 minutes. Visual test, macroscopic test, microscopic test and hardness test already done in this research. The results are there is no defect such as crack, porosity, undercut, and lack of fusion on the visual and macroscopic test. On microscopic test, there is the brittle phase (martensite) in HAZ at Non-PWHT specimen, but after PWHT the martensite transform became martempered phase. FC250 standard hardness value is about 170-235HB, and the result is the hardness value of non-PWHT specimen higher than the standard in HAZ, and the high hardness value of PWHT specimen on weld metal by using NiFe, NiFe-1 and $308 \mathrm{~L}$. So from the filler variation, Ni-CI filler with PWHT is on standard either on phase or on hardness value
\end{abstract}

\section{Introduction}

In an internal combustion engine, cylinder head is a crucial component of combustion engine because cylinder head was located on hotspot which is works at high temperature and high pressure continuously[1]. Cylinder head plays an important role in maintaining the combustion chamber for not to leak so the failure on the cylinder head is highly avoided. Cylinder head is usually made of gray cast iron material. Cast iron generally has low weldability, because of their brittleness and effect of the thermal cycle of welding on their microstructure. Weldability refers to the ability of a material to be joined under the fabrication conditions to form a structure that will perform satisfactorily in the application [2]. Weldability of cast iron depends on the several factors including (i) type of the cast iron (ii) chemical composition of the cast iron (iii) chemical

composition of filler metal (iv) original matrix structure (v) welding process and project/post heat treatment [35]. When cast iron is welded, Generally, 4 regions are formed including

1. Base Metal is an area that is not exposed to heat cycle from welding process.

2. Heat Affected Zone (HAZ). The area that does not melt but has a heat effect resulting in changes on microstructure. During welding, carbon can diffuse into austenite. When cooling occurs, the austenite transforms into martensite. This martensite structure is very brittle and susceptible to crack. The amount of martensite formed depends on the chemical or the type of cast iron and its thermal history. The brittle martensite structure can be changed by tempering using preheat and interpass temperature, with multi-pass welding or with post weld heat treatment.

3. Partial Melted Zone (PMZ). An area is adjacent to HAZ where the heat on the weld area is high enough to cause the base metal to partial melt. This is the most critical area of the weld because in cooling, this area forms white iron (when held at high temperatures long enough carbon soluble) due to the high rate of cooling. This area is very complex and contains many different types of microstructures. If the amount of soluble graphite during welding is sufficiently high and to form a continuous matrix fluid, then there is the possibility that the carbide network is also sustainable, and its causes problem. Since the partial melted area contains a large portion of the hard results, it is the hardest region of welding. The high hardness and low toughness cause this area to be responsible for mechanical problems in cast iron welding. The most effective way to 
reduce the severity of crack problems is to reduce the peak temperature and duration at high temperatures. It can be controlled by heat input, preheat, interpass temperature, good filler metal selection.

4. Fusion Zone is an area formed from melted metal fillers and some dilution from iron casting [6].

Preheat and Post Weld Heat Treatment (PWHT) can reduce the problem of welding HAZ region. Preheat and Post Weld Heat Treatment (PWHT) is primarily used to slow the heating and cooling rates of metals [7]. Preheat is used to control the microstructure of the weld area. Preheating can slow down the rate of cooling. A slow cooling rate can also help minimize residual stresses. Preheat is also done to prevent crack caused by temperature gradient and thermal stress, reducing residual stress on casting, reducing distortion, reducing hardness in HAZ, reducing temperature gradient at dissimilar welding, reducing hydrocarbon contamination [6].

Post Weld Heat Treatment (PWHT) can be defined as a heat treatment process after welding, commonly used to improve the nature of the welding result [8]. The function of Post Weld Heat Treatment is to refine martensite in weld metal and HAZ, which aims to reduce hardness and increase toughness and reduce the residual stress that occurs during the welding process. The PWHT process can be carried out based on the specific alloys and fillers used. Also the dimensions, joint design, and welding parameters are also influential [9]. Post weld heat treatment generally uses temperatures below critical temperatures (before transforming into austenite). The temperature used depends on the type of material used. With temperatures below these critical temperatures, it creates a finer structure that reduces the possibility of brittle failure.

\section{Experimental Procedure}

The samples used are part of the cylinder head that failure is fretting with the operating life of 30000-35000 hours. Cylinder head is divided into 4 pieces with each size $80 \times 20 \times 20 \mathrm{~mm}$. Welding is performed on all four specimens by using the different fillers. Welding parameters used are as follows.

Table 1. Welding Parameters

\begin{tabular}{|c|l|l|}
\hline No. & \multicolumn{1}{|c|}{ Parameters } & \multicolumn{1}{c|}{ Details } \\
\hline 1 & Current & $140 \mathrm{~A}$ \\
\hline 2 & Voltage range & $17-21 \mathrm{~V}$ \\
\hline 3 & Polarity & DCEP \\
\hline 4 & Travel Speed & $25 \mathrm{~cm} / \mathrm{min}$ \\
\hline 5 & Gas composition & $100 \%$ Argon \\
\hline 6 & Preheat & $250^{\circ} \mathrm{C}$ \\
\hline 7 & Electrode Diameter & $2.4 \mathrm{~mm}$ \\
\hline
\end{tabular}

After welding, the specimen is divided into 2 parts. The first part becomes a non -PWHT specimen while the second part is treated with PWHT in the furnace. After that PWHT is carried out at $650^{\circ} \mathrm{C}$ with holding time 90 minutes.

A. Visual Test

This test is done by checking visually to check for defects that occur on the surface of the weld such as porosity, undercut, or crack on the weld surface.

B. Macroscopic Test

Macroscopic tests were performed on specimen samples to determine the presence or absence of defects on the inside of the weld such as the presence of an internal crack, incomplete fusion, blow hole and porosity. Macro testing was performed using a lowmagnification optical microscope that ranged from 4-8 times the magnification in which the specimen to be observed was first etching use Marble's solution.

C. Microscopic Test

The test is performed to see the microstructure formed on the specimen. The etching solution used in this test was Nital solution $(1 \mathrm{ml} \mathrm{HNO} 3+20 \mathrm{ml}$ Alcohol) and observed by optical microscope with magnification 100x, 200x and 500x

D. Hardness Test

Hardness test used is Brinell indentor with diameter $1 \mathrm{~mm}$ and load $30 \mathrm{Kgf}$. This test is performed to determine the hardness distribution in base metal, HAZ and weld metal for each variable.

\section{E. XRD Test}

XRD testing is done to determine the compound or the phase formed on the welding result.

\section{Results and Discussions}

\subsection{Visual Test Result Analysis}

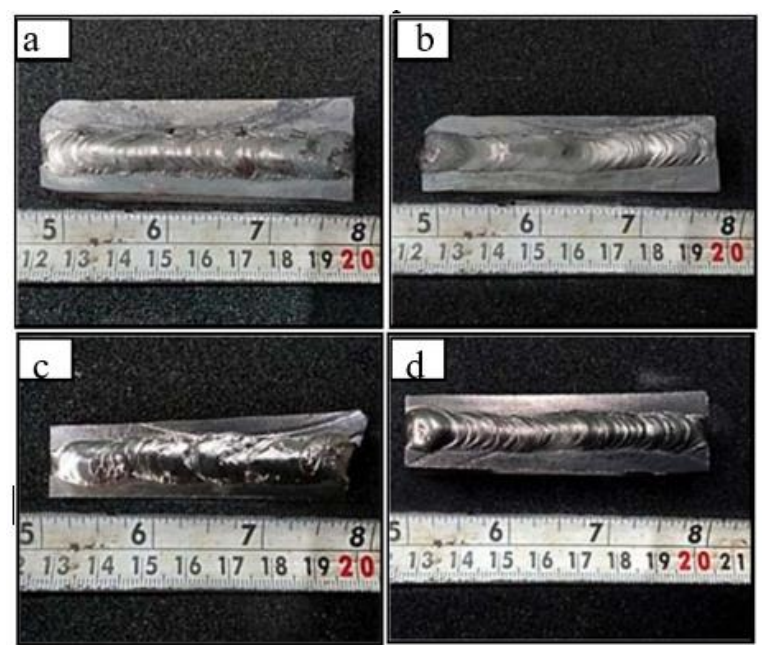

Fig. 1. Specimen welded by using (a) Ni-CI (b) NiFe-1 (c) $\mathrm{NiFe}$ (d) 308L filler

After welding on specimens using weld parameters as shown in table 1 , visual observation was done to determine the quality of welds by identifying the visible weld defects including undercut, bead porosity, surface crack, and burn through. The following visual observations on the welded specimen test results. 
After the welding process is done on the specimen sample, then the visual observation on the surface of the welding result shows that the welding result on the whole specimen does not indicate the existence of welding defect, either crack, undercut or porosity on the surface of the weld.

\subsection{Macroscopic Test Result Analysis}

To identify the possibility of the imperfection of the joining process on the inside of the weld in the form of lack of fusion or lack of penetration, then the macroscopic observation process is then performed on samples of specimens of PWHT and non-PWHT that have been cut on the cross-section of the weld area. This is intended to facilitate the identification process of the weld area. Here are macro test results :

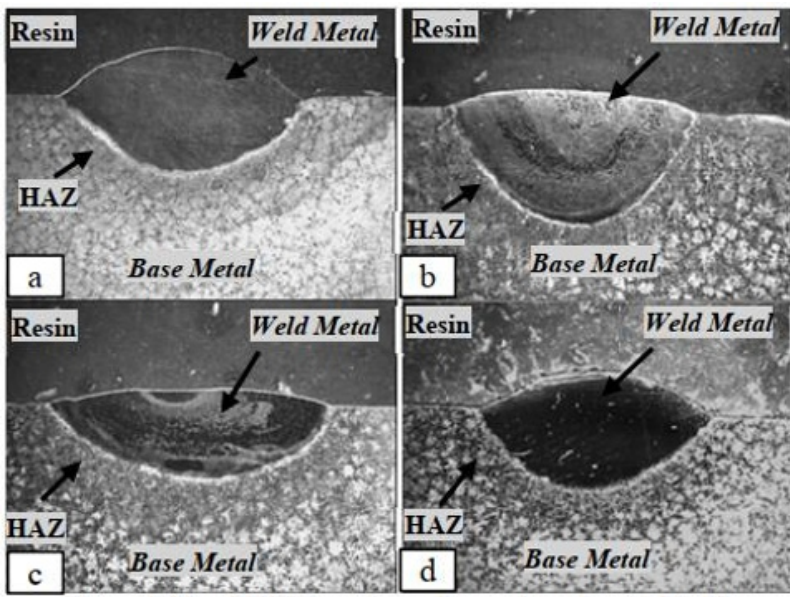

Fig. 2. Non-PWHT specimen figures by using (a) Ni-CI (b) $\mathrm{NiFe}$ (c) $\mathrm{NiFe}-1$ (d) $308 \mathrm{~L}$ filler

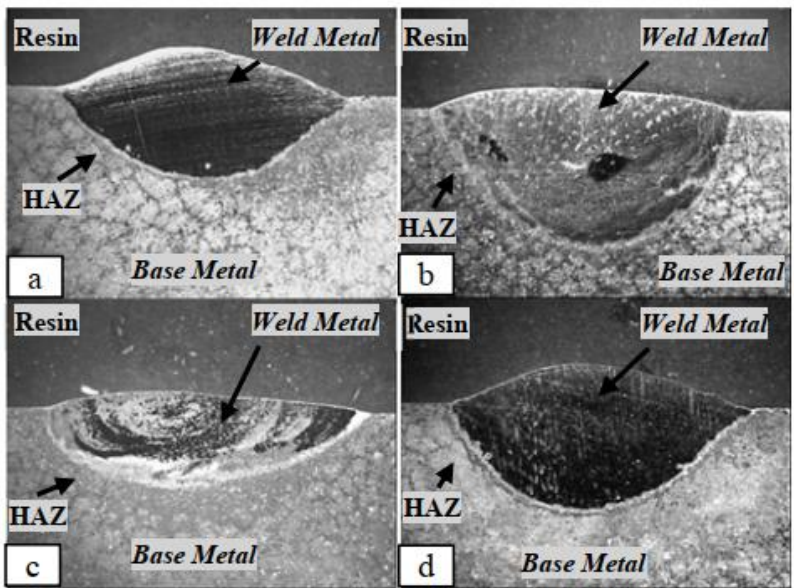

Fig. 3. PWHT specimen figures by using (a) Ni-CI

(b) $\mathrm{NiFe}$ (c) $\mathrm{NiFe}-1$ (d) 308L filler

In the macroscopic test results found that in all specimens, no non-fusion area was found between weld metal and base metal. The welding process performed on each filler variable also gives a relatively different effect on the bead profile and size on the weld. From the results of this test also obtained the visualization of areas that occur due to the welding process consisting of base metal, HAZ, and weld metal was for all specimens found no distribution of porosity, blowhole or another internal defect in the weld area.

\subsection{Microscopic Test Result Analysis}

Microscopic test was performed to observe the microstructures that formed on each specimen with an optical microscope at a magnification ranging from 100500 times. Microscopic test results are obtained as shown below.

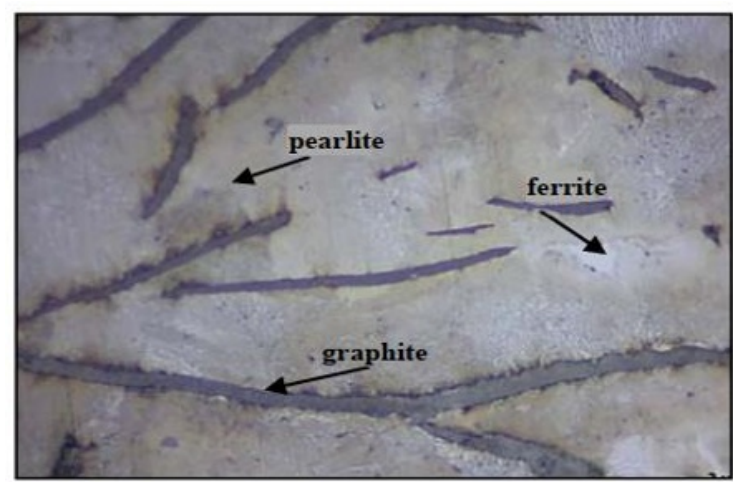

Fig. 4. Original material microstructure magnification 500x

From microscopic testing on the original material gray cast iron FC 250, obtained the result of ferrite microstructure graphite with pearlite matrix.

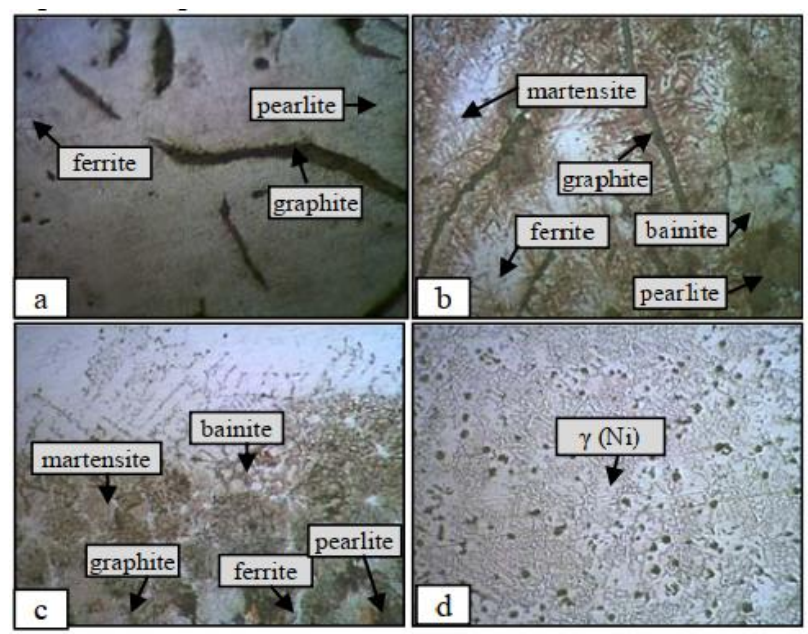

Fig. 5. Microstructure of non-PWHT specimen by using Ni-CI filler (a) base metal (b) HAZ (c) fusion line (d) weld metal

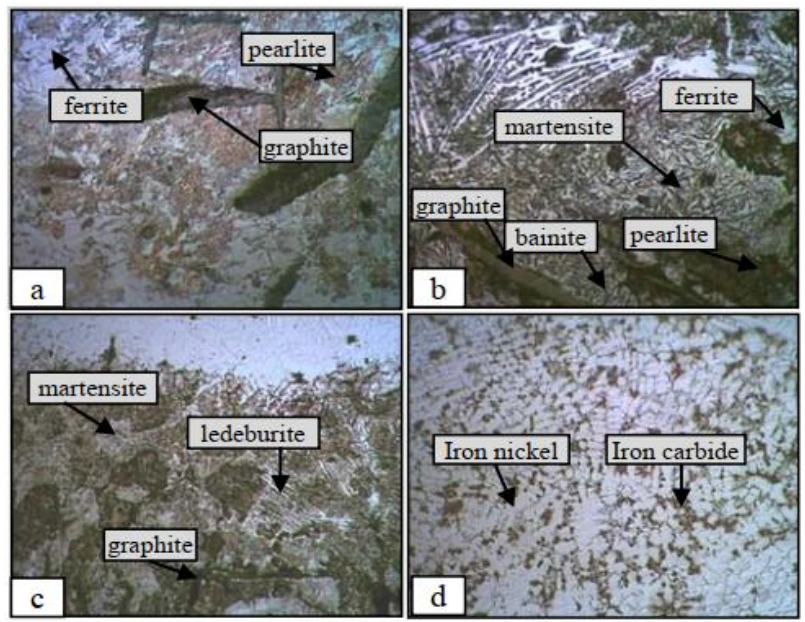

Fig. 6. Microstructure of non-PWHT specimen by using NiFe1 filler (a)base metal (b)HAZ (c) fusion line (d) weld metal 


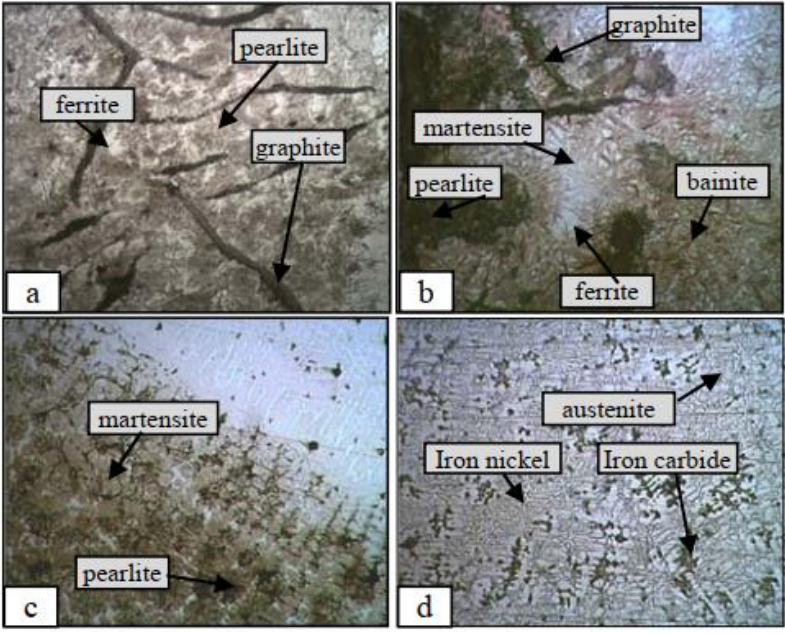

Fig. 7. Microstructure of non-PWHT specimen by using NiFe filler (a)base metal (b) HAZ (c) fusion line (d) weld metal

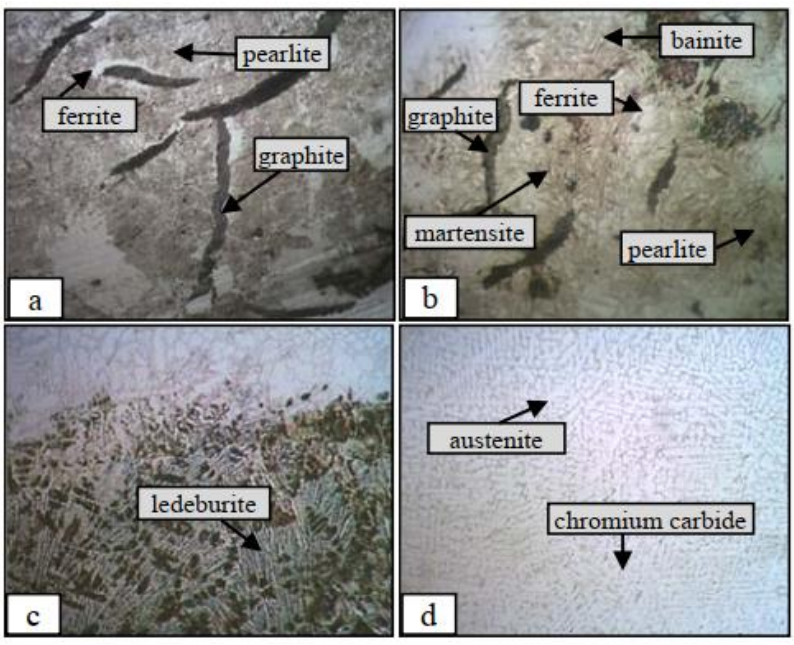

Fig. 8. Microstructure of non-PWHT specimen by using 308L filler (a ) base metal (b) HAZ (c) fusion line (d) weld metal

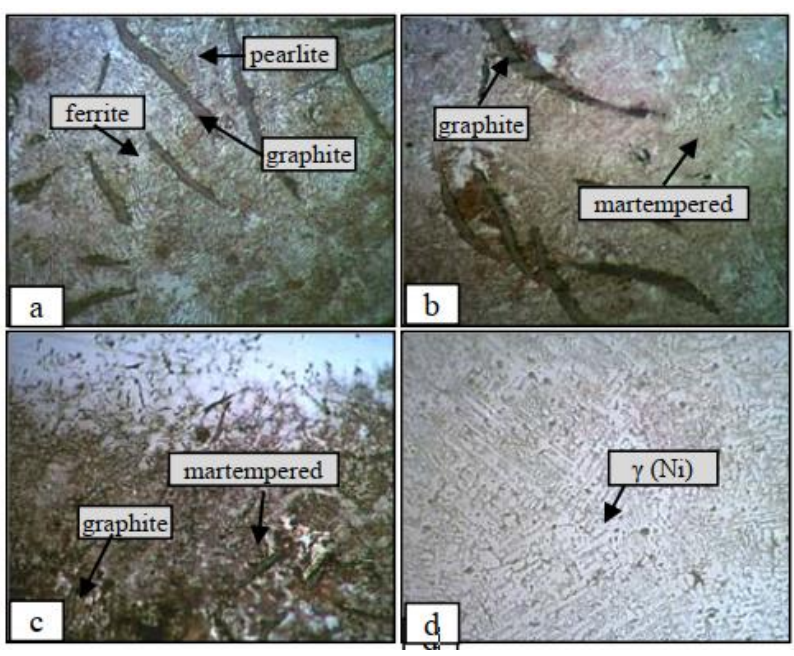

Fig. 9. Microstructure of PWHT specimen by using Ni-CI filler (a) base metal (b) HAZ (c) fusion line (d) weld metal

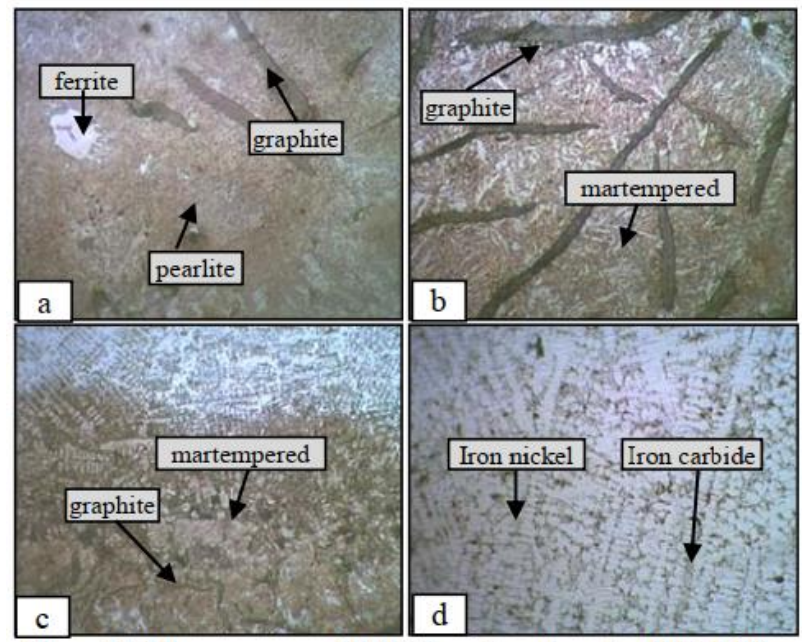

Fig. 10. Microstructure of PWHT specimen by using $\overline{\mathrm{NiFe}}-1$ filler (a) base metal (b) HAZ (c) fusion line (d) weld metal

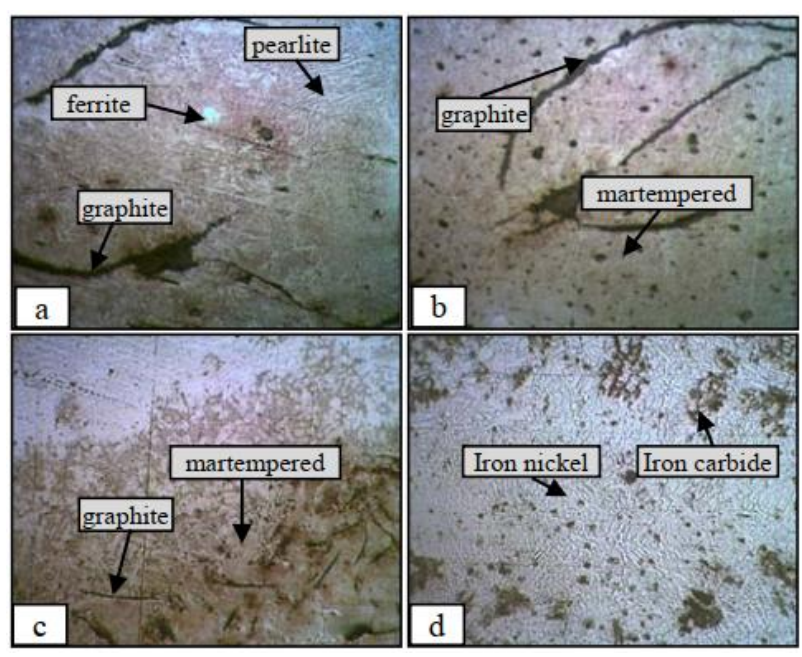

Fig. 11. Microstructure of PWHT specimen by using $\mathrm{NiFe}$ filler (a) base metal (b) HAZ (c) fusion line (d) weld metal

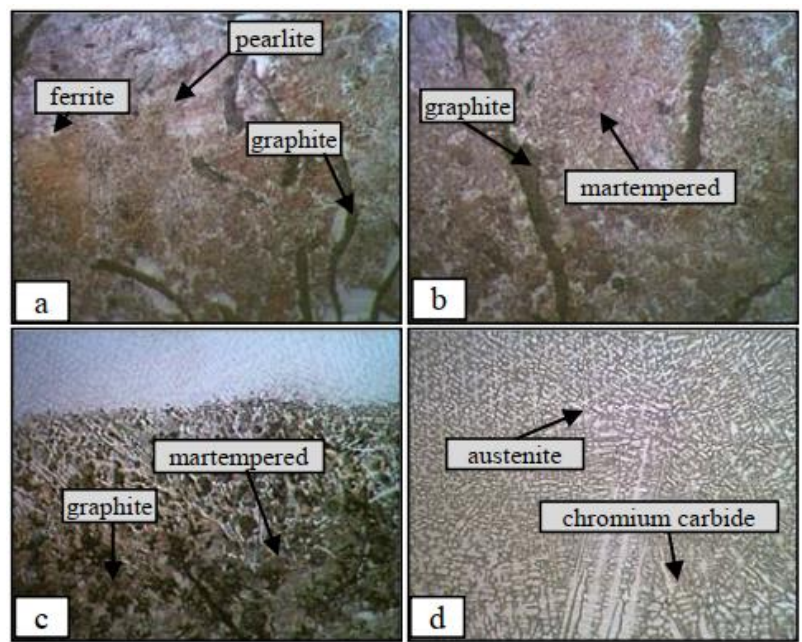

Fig. 12. Microstructure of PWHT specimen by using 308L filler (a) base metal (b) HAZ (c) fusion line (d) weld metal 
Based on microscopy test and hardness test performed on non-PWHT welding specimens, it was found that there is no phase change in the base metal area, where the phase formed on the base metal of the welded specimen is the same as the phase on the original cylinder head, are ferrite, graphite, and pearlite.

While in the HAZ area, on non-PWHT specimens the results obtained where the $\mathrm{Ni}-\mathrm{CI}$ filler has the same phase with the $\mathrm{NiFe}$ filler weld is martensite, bainite, graphite, pearlite, and ferrite. While on the weld filler $\mathrm{NiFe}-1$ found the same phase with welds with a 308L filler of martensite, bainite, graphite, pearlite, ferrite, and ledeburite. Thus it can be identified that the welding process carried out without the PWHT process, always results in a martensitic phase in the four types of fillers. The carbon content of gray cast iron is relatively high and the cooling rate process which is not slow lead to the martensitic phase. The presence of a martensite phase will result in a hard but brittle material structure, with low toughness, and low fatigue resistance material [6]. While the cylinder head working at high temperature and fluctuations will cause the shrink and expand on the material inside the combustion chamber. The material with the brittle phase will have low elongation so that the ability to shrink and expand due to the heat will be very limited and will have greater possibility of experiencing premature failure compared with the material with nonmartensite phase. So from all filler welding process without process PWHT Which produces a martensite phase can be said to be less suitable to be applied under conditions of cylinder head operation load.

While in the weld metal area, for non PWHT specimen obtained phases are $\gamma-\mathrm{Ni}$ for $\mathrm{Ni}-\mathrm{Ci}$ filler, iron nickel, iron carbide and austenite for $\mathrm{NiFe}$ filler, for $\mathrm{NiFe}-1$ filler is iron-nickel and iron carbide. While on the filler $308 \mathrm{~L}$ microstructure formed that is austenite and chromium carbide.

The PWHT process was performed on a welded sample with 4 different fillers at temperature $650^{\circ} \mathrm{C}$ and holding time for 1.5 hours. After the PWHT process on 4 weld samples, the results were identified and compared with the previous results by microscopic testing and hardness testing. Based on the results of microscopic testing it was found that the phase composition in the base metal region did not change. While in the HAZ region found the occurrence of structural changes and mechanical properties. In the martensite HAZ region was not found in post-weld samples of the PWHT process. The phases that occur in Ni-CI, Ni-Fe, and NiFe-1 filler samples after PWHT process are martempered and graphite. While on the filler 308L after phase PWHT process that occurs is martempered, graphite, and ledeburite.

\subsection{Hardness Test Result Analysis}

To determine the hardness of each specimen, a hardness test was tested on the weld metal, HAZ and base metal regions where $5 \mathrm{x}$ indentation was performed using a 1 $\mathrm{mm}$ diameter Brinell indentor with a loading of $30 \mathrm{Kgf}$ which refers to ASTM E10 standard. Here are the results of hardness testing on each specimen.
Based on the data below, the average hardness value in each region before and after PWHT experienced a difference. In all specimens, the hardness values decreased in the base metal and HAZ regions after the PWHT process, whereas in the weld metal region, the trend was an increase. Specimen with filler 308L shows the highest increase of hardness value. However in specimens with $\mathrm{Ni}-\mathrm{CI}$ fillers, there is no tendency to increase in the weld metal region

Table 2. The average of hardness distribution for each specimen

\begin{tabular}{|c|c|c|c|c|c|c|}
\hline \multirow{3}{*}{ Filler } & \multicolumn{6}{|c|}{ Hardness Value (HB) } \\
\cline { 2 - 7 } & Non-PWHT Specimen & \multicolumn{2}{|c|}{ PWHT Specimen } \\
\cline { 2 - 7 } & Base & Haz & Weld & Base & Haz & Weld \\
\hline Ni-CI & 228.12 & 489 & 194.74 & 196.36 & 223.78 & 195.92 \\
\hline NiFe-1 & 219.06 & 454.5 & 327.92 & 203.42 & 231 & 368.46 \\
\hline NiFe & 231.24 & 442.54 & 311.1 & 196.2 & 249.94 & 403.48 \\
\hline $308 \mathrm{~L}$ & 216.1 & 432.3 & 367.02 & 206.6 & 319.86 & 594.14 \\
\hline
\end{tabular}

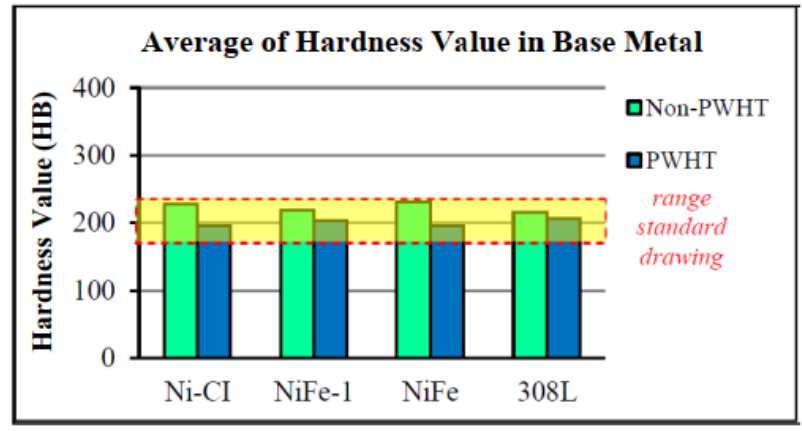

Fig. 13. Average of hardness value diagram in base metal

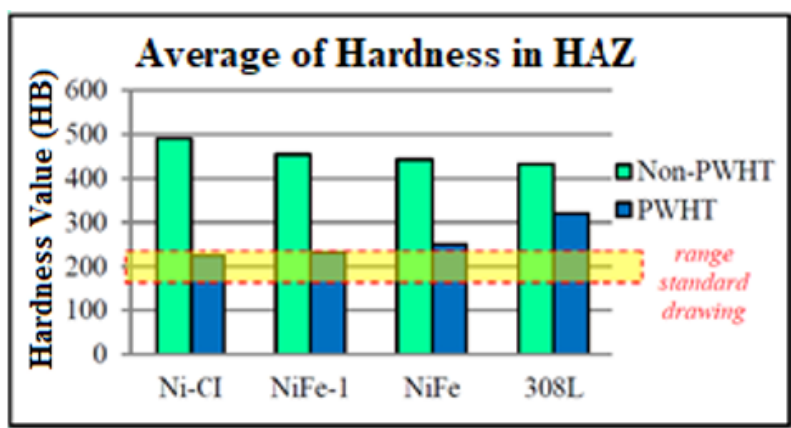

Fig. 14. Average of hardness value diagram in HAZ

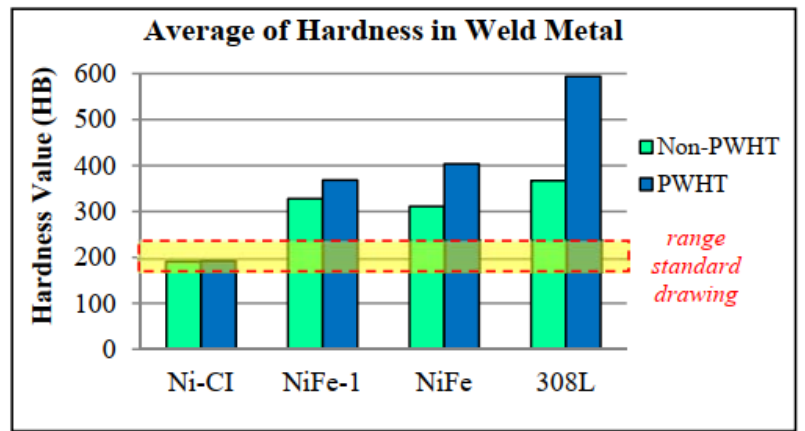

Fig. 15. Average of hardness value diagram in weld metal 
To determine the cause of the increase of hardness value in this weld metal, then XRD testing on the weld metal, on the four specimens PWHT and Non-PWHT. In $\mathrm{Ni}$-CI weld metal specimens it is found that peak of highest intensity is $\gamma-\mathrm{Ni}$, which means that the phaseforming compound in weld metal is not changed due to PWHT process. The presence of Ni content as a very high austenite stabilizer $(98 \%)$ causes the austenite formed before PWHT to withstand the formation of carbide compounds to room temperature. So that the phase formed remains $\gamma-\mathrm{Ni}$ in the process after PWHT. This is supported by the results of the XRD test below which shows the $\gamma$-Ni peak still formed before or after the PWHT process.

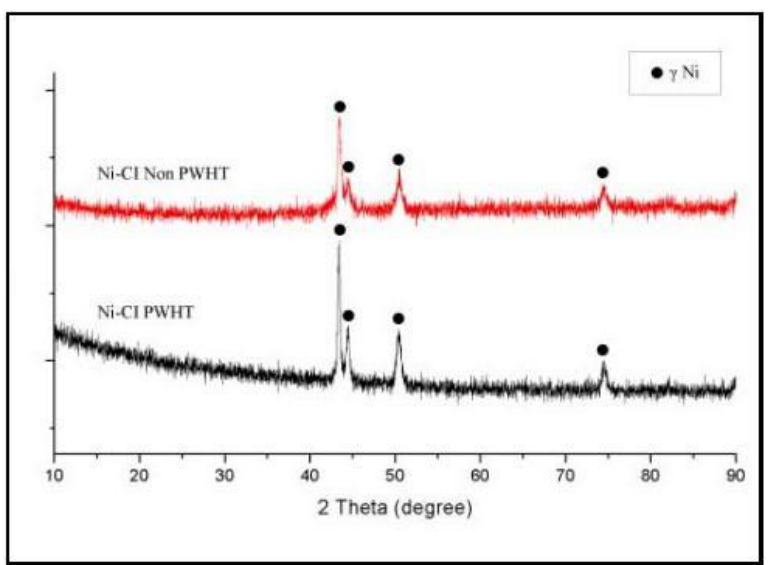

Fig. 16. XRD result on Ni-CI weld metal

Then on the NiFe-1 filler, a significant increase in the value of hardness occurs due to the PWHT process, the carbon present in the base metal diffuses into the weld metal and causes carbide precipitation. Compared with the Ni-CI filler which has $98 \%$ nickel, the presence of nickel element as austenite stabilizer in $\mathrm{NiFe}-1$ which is only $57.22 \%$ is not enough composition to stabilize austenite to room temperature. The PWHT process with a temperature of $650{ }^{\circ} \mathrm{C}$ causes the release of $\mathrm{Fe}$ bonds with $\mathrm{Ni}$ and causes the bonding of $\mathrm{Fe}$ to carbon and forms a high-hardness iron carbide compound, as evidenced by the XRD test in Figure 17.

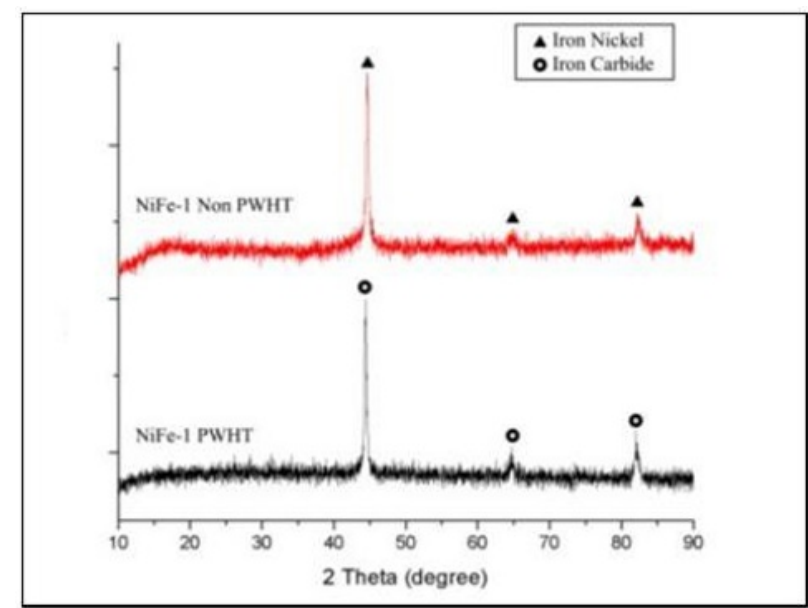

Fig. 17. XRD result on NiFe-1 weld metal
Similarly, NiFe filler specimens have a nickel content of $45 \%$. After the PWHT process, the intensity that occurs changes from iron-nickel and austenite turned into iron carbide is also caused by inadequate levels of Ni in weld metal so that not enough to stabilize the existence of austenite to room temperature, XRD testing reinforces this in Figure 18.

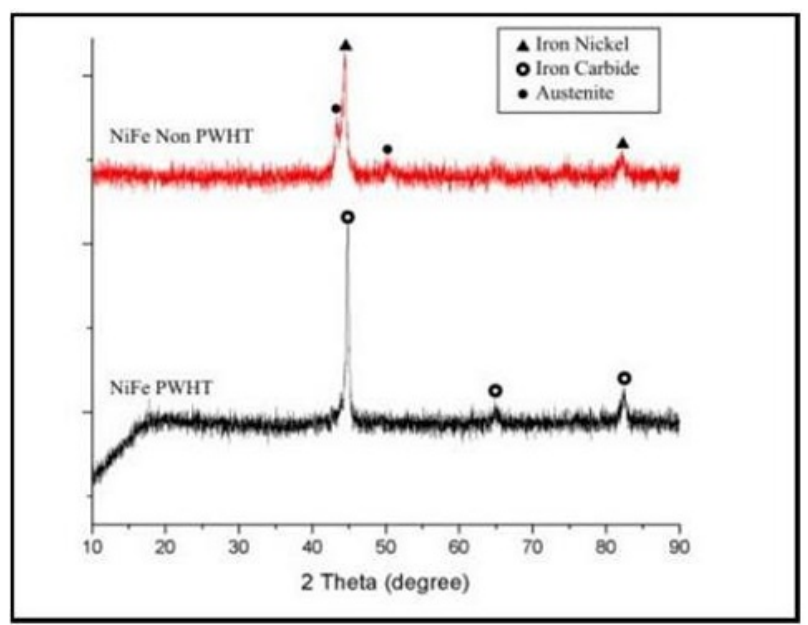

Fig. 18. XRD result on $\mathrm{NiFe}$ weld metal

While at $308 \mathrm{~L}$ a significant increase in hardness in the weld metal area, is caused by the increase of carbideforming elements such as $\mathrm{Cr}$ in areas rich in carbon content. This allows the carbon to bind to the element and form a precipitate during the PWHT process. The presence of precipitation of this carbide makes the hardness value after PWHT process increases [10]. XRD test results in Fig19 support the emergence of carbides after the PWHT process.

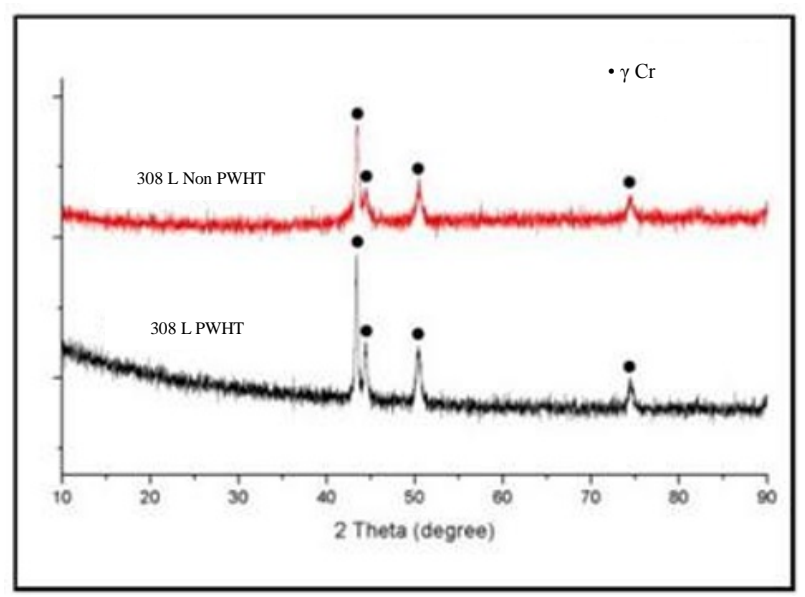

Fig. 19. XRD result on $308 \mathrm{~L}$ weld metal

\section{Conclusion}

Based on the results of research that has been done, obtained the following conclusions.

1. The filler variation does not affect the microstructure formed in the base metal and HAZ regions, but it affects the fusion line and weld metal 
regions where the microstructure formed depends on the filler composition used.

2. The filler variation does not affect the hardness value in the base metal area but influences the HAZ and weld metal areas.

3. Post-Weld Heat Treatment at $650^{\circ} \mathrm{C}$ with a holding time of 90 minutes greatly affects the microstructures formed in the HAZ region where martensite transform into martempered and then in the HAZ region there is a decrease in hardness value for all fillers. However, in the weld metal region, there is an increase in hardness on the $\mathrm{NiFe}-1, \mathrm{NiFe}$ and $308 \mathrm{~L}$ fillers, whereas in $\mathrm{Ni}-\mathrm{CI}$ there is no change in hardness value.

4. Welding by using Ni-CI filler and PWHT Treatment showed weld results that best the FC250 criteria standard; this is indicated by: - The absence of welding defects (porosity, blowhole, crack, undercut)

- The absence of brittle phase (martensite) in the microstructure

- Has an average hardness of $195.92 \mathrm{HB}$ in weld metal area, 223.78 HB in HAZ area, 196.36 HB in base metal area. Then welding by using Ni-CI filler with PWHT treatment can be recommended as repairing method for cylinder head FC250.

\section{References}

1. Morsy,M.A., E.El-Kashif. 2011. Repair Maintenanc of Diesel Engine Cylinder Head. Journal of American Science.

2. Kelly , T. J., R. A. Bishel, R. K. Wilson. 1985. Welding of Ductile Iron with Ni-Fe-Mn Filler Metal.

3. Pouranvari,M. 2010. On the Weldability of Grey Cast Iron Using Nickel Based Filler Metal. Elsevier.

4. Butola, Ravi, Jitendra Kumar, Vikas Verma, Prakash Mahara. 2013. Study of Microstructure, Impact Strength on Manual Metal Arc Welding Of Gray Cast Iron Using ENiFe-CI Filler Metal.

5. Pradeshiram, S.P. Tewari, and Jyotiprakash. 2012. A Review on Metallurgy of Welding of Cast Iron and Effect of Preheat. Indian journal of research.

6. ASM Handbook Volume 6 WELDING, BRAZING, AND SOLDERING. ASM International.

7. Srivastava, B. K. , S. P. Tewari and J. Prakash. 2010. A Review on Effect of ARC Welding Parameters on Mechanical Behavior of Ferrous Metals/Alloys. International Journal of Engineering Science and Technology Vol. 2

8. Funderburk, R. S. 1998. Post Weld Heat Treatment. In R. S. Funderburk, Welding Innovation.

9. Sharma, S. D., Saluja, R., \& Moeed, K. (2013). A review on Effect of Preheating and/or Post Weld Heat Treatment (PWHT) on Hardened Steel. International Journal of Research in Mechanical Engineering and Technology.

10.Olden, Vigdis. 2003. The Effect Of Pwht On The Material Properties And Micro Structure In Inconel
625 And Inconel 725 Buttered Joints. The 22nd International Conference on Offshore Mechanics \& Arctic Engineering. 